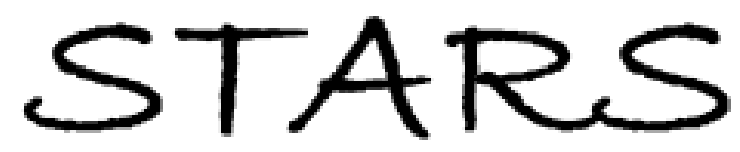

University of Central Florida

STARS

$1-1-2010$

\title{
Deep-ultraviolet photodetectors from epitaxially grown NixMg1-xO
}

\author{
J. W. Mares \\ University of Central Florida \\ R. C. Boutwell \\ University of Central Florida \\ M. Wei \\ University of Central Florida \\ A. Scheurer \\ University of Central Florida \\ W. V. Schoenfeld \\ University of Central Florida
}

Find similar works at: https://stars.library.ucf.edu/facultybib2010

University of Central Florida Libraries http://library.ucf.edu

This Article is brought to you for free and open access by the Faculty Bibliography at STARS. It has been accepted for inclusion in Faculty Bibliography 2010 s by an authorized administrator of STARS. For more information, please contact STARS@ucf.edu.

\section{Recommended Citation}

Mares, J. W.; Boutwell, R. C.; Wei, M.; Scheurer, A.; and Schoenfeld, W. V., "Deep-ultraviolet photodetectors from epitaxially grown NixMg1-xO" (2010). Faculty Bibliography 2010s. 507.

https://stars.library.ucf.edu/facultybib2010/507

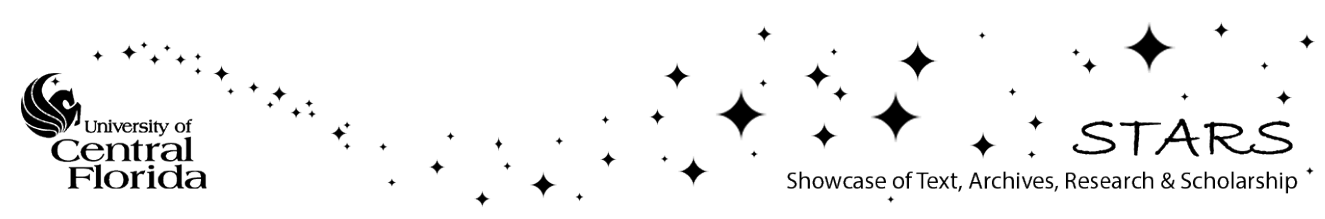




\section{Deep-ultraviolet photodetectors from epitaxially grown $\mathrm{Ni}_{\mathrm{x}} \mathrm{Mg}_{1-\mathrm{x}} \mathrm{O}$}

Cite as: Appl. Phys. Lett. 97, 161113 (2010); https://doi.org/10.1063/1.3503634

Submitted: 21 July 2010 . Accepted: 28 September 2010 . Published Online: 22 October 2010

J. W. Mares, R. C. Boutwell, M. Wei, A. Scheurer, and W. V. Schoenfeld

\section{ARTICLES YOU MAY BE INTERESTED IN}

Fabrication and photoresponse of a pn-heterojunction diode composed of transparent oxide semiconductors, $\mathrm{p}-\mathrm{NiO}$ and $\mathrm{n}-\mathrm{ZnO}$

Applied Physics Letters 83, 1029 (2003); https://doi.org/10.1063/1.1598624

A review of $\mathrm{Ga}_{2} \mathrm{O}_{3}$ materials, processing, and devices

Applied Physics Reviews 5, 011301 (2018); https://doi.org/10.1063/1.5006941

Band engineering of $\mathrm{Ni}_{7-x} \mathrm{Mg} \mathrm{g}_{x} \mathrm{O}$ alloys for photocathodes of high efficiency dye-sensitized solar cells

Journal of Applied Physics 112, 123703 (2012); https://doi.org/10.1063/1.4769210

\section{Applied Physics Reviews} Now accepting original research 


\title{
Deep-ultraviolet photodetectors from epitaxially grown $\mathrm{Ni}_{\mathrm{x}} \mathrm{Mg}_{1_{-\mathrm{x}} \mathrm{O}} \mathrm{O}$
}

\author{
J. W. Mares, ${ }^{\text {a) }}$ R. C. Boutwell, M. Wei, A. Scheurer, and W. V. Schoenfeld \\ CREOL/The College of Optics and Photonics, University of Central Florida, 4000 Central Florida Blvd., \\ Orlando, Florida 32816, USA
}

(Received 21 July 2010; accepted 28 September 2010; published online 22 October 2010)

\begin{abstract}
Deep-ultraviolet (DUV) photodetectors were fabricated from high quality $\mathrm{Ni}_{\mathrm{x}} \mathrm{Mg}_{1-\mathrm{x}} \mathrm{O}$ epitaxially grown by plasma-assisted molecular beam epitaxy on an approximately lattice matched $\mathrm{MgO}\langle 100\rangle$ substrate. A mid-range $\mathrm{Ni}$ composition $(\mathrm{x}=0.54) \mathrm{Ni}_{\mathrm{x}} \mathrm{Mg}_{1-\mathrm{x}} \mathrm{O}$ film was grown for DUV $\left(\lambda_{\text {peak }}\right.$ $<300 \mathrm{~nm}$ ) photoresponse and the film was characterized by reflected high-energy electron diffraction, Rutherford backscattering spectroscopy, x-ray diffraction, and optical transmission measurements. Photoconductive detectors were then fabricated by deposition of symmetric interdigitated contacts $(10 \mathrm{~nm} \mathrm{Pt} / 150 \mathrm{~nm} \mathrm{Au})$ with contact separations of 5,10 , and $15 \mu \mathrm{m}$. The detectors exhibited peak responsivities in the DUV $\left(\lambda_{\text {peak }} \approx 250 \mathrm{~nm}\right)$ as high as $12 \mathrm{~mA} / \mathrm{W}$, low dark currents $\left(\mathrm{I}_{\mathrm{dark}}<25 \mathrm{nA}\right)$, and DUV:visible rejection ratio of approximately 800:1. () 2010 American Institute of Physics. [doi:10.1063/1.3503634]
\end{abstract}

Various binary and ternary oxide semiconductors have been of growing interest recently as potential candidates for application in deep ultraviolet (DUV, $\lambda<300 \mathrm{~nm}$ ) optoelectronic technologies. Semiconductors with direct band gaps greater than $4.35 \mathrm{eV}$ find application in solar blind detection of radiation naturally attenuated by stratospheric ozone $(\lambda$ $<285 \mathrm{~nm})$. In medicine, the germicidal applications of ultraviolet-C light (UVC, $\lambda<280 \mathrm{~nm}$ ) are well known and exploited as are its uses in the treatment of skin conditions such as psoriasis, eczema, and acne. Likewise, in manufacturing and industry DUV light is exploited in diverse applications such as photochemical processing, compound curing, and transistor erasure in erasable programmable read-only memory chips.

Here we present the epitaxial growth and characterization of approximately lattice matched epitaxial $\mathrm{Ni}_{\mathrm{x}} \mathrm{Mg}_{1-\mathrm{x}} \mathrm{O}$ on single-crystal $\langle 100\rangle \mathrm{MgO}$ for DUV photoconductors. This ternary compound is highly structurally compatible with the well exploited cubic $\mathrm{Zn}_{\mathrm{x}} \mathrm{Mg}_{1-\mathrm{x}} \mathrm{O}$ (Refs. 1 and 2) and has also already proven to be a useful optoelectronic material unto itself. ${ }^{3,4}$ In complement to $\mathrm{Zn}_{\mathrm{x}} \mathrm{Mg}_{1-\mathrm{x}} \mathrm{O}$, which exhibits strong $n$-type propensity, ${ }^{5-8} \mathrm{Ni}_{\mathrm{x}} \mathrm{Mg}_{1-\mathrm{x}} \mathrm{O}$ exhibits a strong intrinsic $p$-type propensity and can also be $p$-doped extrinsically. ${ }^{9-15}$ $\mathrm{NiO}$ and $\mathrm{MgO}$ are mutually miscible and the complete compositional range of $\mathrm{Ni}_{\mathrm{x}} \mathrm{Mg}_{1-\mathrm{x}} \mathrm{O}$ maintains a rocksalt cubic (B1) crystal structure with only $\varepsilon_{\mathrm{MgO}}=0.8 \%$ deviation in lattice constant $\left(\mathrm{a}_{\mathrm{NiO}}=4.177 \AA, \mathrm{a}_{\mathrm{MgO}}=4.213 \AA\right) .{ }^{16-18}$ Thus the ternary material is approximately lattice matched to commercially available $\mathrm{MgO}$ substrates. The band gap of $\mathrm{NiO}$ is approximately $3.6 \mathrm{eV}$ (direct, $\lambda=344 \mathrm{~nm}$ ) and the ternary $\mathrm{Ni}_{\mathrm{x}} \mathrm{Mg}_{1-\mathrm{x}} \mathrm{O}$ exhibits band gap tunability across the 3.6-7.8 $\mathrm{eV}$ spectral region. Although prior efforts of $\mathrm{NiMgO}$ film growth and application have been conducted, ${ }^{3,4,16-18}$ no literature exists on devices fabricated from molecular beam epitaxy (MBE) grown $\mathrm{NiMgO}$ thin films nor has there been any report of $\mathrm{NiMgO}$ growth on lattice matched singlecrystal substrates.

In this research, epitaxial $\mathrm{Ni}_{\mathrm{x}} \mathrm{Mg}_{1-\mathrm{x}} \mathrm{O}$ was grown, characterized and exploited in DUV photoconductors. The film

${ }^{a)}$ Electronic mail: jmares@mail.ucf.edu. was grown as initially presented in Refs. 1 and 19, with subsequent refinements in growth parameters. In brief, the undoped (or unintentionally doped) film was grown with an MBE system, employing a radio-frequency oxygen plasma source. Elemental Mg and $\mathrm{Ni}$ (purity $99.99 \%$ and $99.9995 \%$, respectively) were thermally evaporated from Knudsen cells. The film was grown on a single-crystal $\mathrm{MgO}\langle 100\rangle$-oriented 1 in. $^{2}$ substrate (MTI Crystal) with surface roughness measured to be less than $\sim 5 \AA$. The substrate was cleaned in acetone, isopropanol, and de-ionized water ultrasonic baths then dried with $\mathrm{N}_{2}$ flow. The substrate was degassed in a separate, vacuum-connected preparation chamber prior to growth. During growth $\mathrm{O}_{2}$ flow rates ranged from 0.5 to 1.5 standard cubic centimeter per minute and substrate temperature was fixed at $700{ }^{\circ} \mathrm{C}$. To improve surface quality for growth, a homoepitaxial $\mathrm{MgO}$ layer was first grown.

To assess film surface order in situ, reflection-high energy electron diffraction (RHEED) monitoring was carried out periodically during growth. Film composition and thickness were determined by Rutherford Backscattering (RBS) using $2.25 \mathrm{MeV} \mathrm{He}{ }^{2+}$ particles and film thickness was confirmed by a Veeco Dektak 150 Profiler. X-ray diffraction (XRD) characterization was carried out with a Rigaku D/MAX x-ray diffractometer using $\mathrm{Cu} K_{\alpha}$ radiation ( $\lambda$ $=1.54056 \AA)$. Cataloged information about XRD spectra was obtained from JCPDS card numbers 045-0946 (MgO), 78-0643, and 89-7130 (NiO). Transmission spectrophotometry was carried out at room temperature using a Cary 500 UV-VIS spectrophotometer.

Photoconductive devices were then fabricated by standard photolithographic techniques. Conventional interdigitated contact patterns were designed with 5, 10, and $15 \mu \mathrm{m}$ contact separations and a total device area of $1 \mathrm{~mm}^{2}$. Contact metals were evaporated by an electron beam deposition system (Temescal FC-2000). Pt/Au contact metals $(10 \mathrm{~nm} /$ $150 \mathrm{~nm}$ ) were chosen for Ohmic behavior to reduce or eliminate potential gain effects resulting from interfacial charge accumulation. Spectral responsivity measurements were conducted at room-temperature by illuminating the devices with a Xe lamp $(300 \mathrm{~W})$ passed through a monochromater while bias voltage and device current measurement were provided 

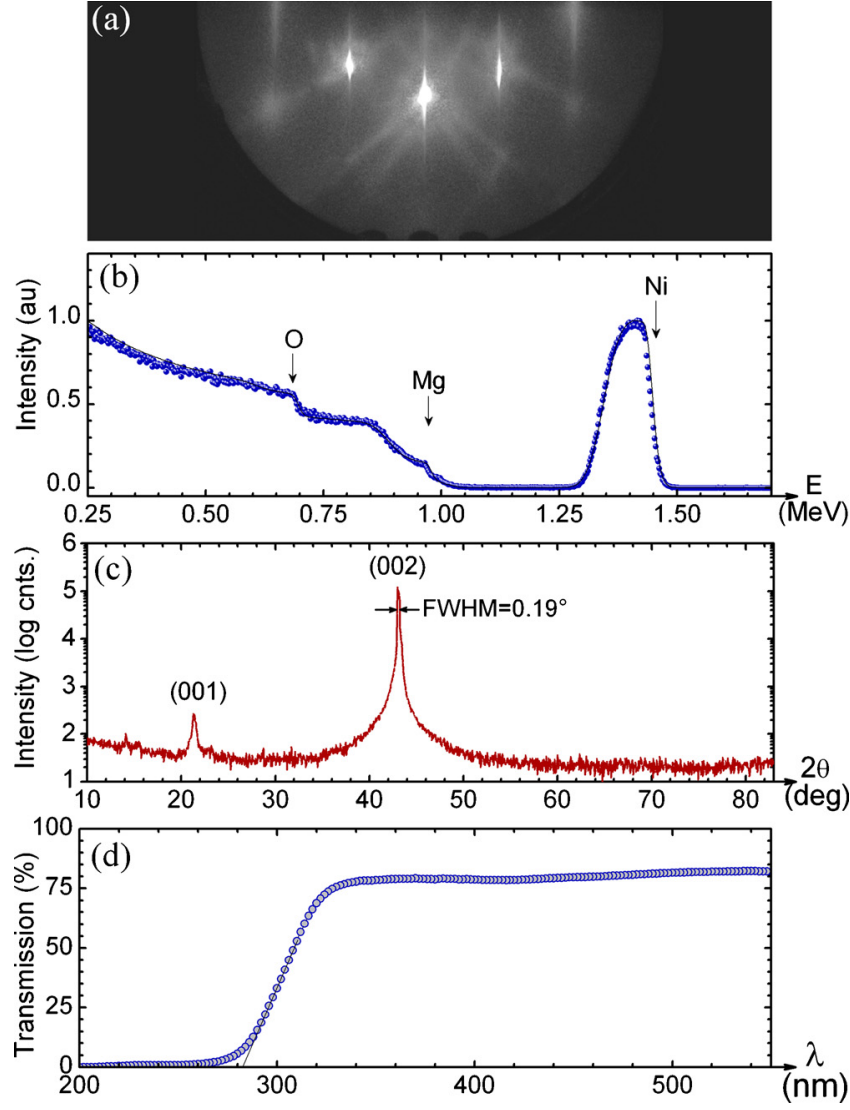

FIG. 1. (Color online) Characterizations of the $\mathrm{Ni}_{0.54} \mathrm{Mg}_{0.46} \mathrm{O}$ film including (a) postgrowth RHEED indicating good surface order, (b) RBS spectrum of the film quantifying the composition, (c) XRD spectrum showing the highly oriented character of the film, and (d) optical transmission spectrum illustrating the UVC absorption edge.

by a Keithley 2400 source-meter. Because of the persistent photoconductivity exhibited by these devices, a typical lock-in amplification scheme is not applicable. Rather, light exposure was shuttered and illumination time was set to $3 \mathrm{~s}$, which is greater than the time needed to saturate response. Responsivity values are corrected for both contact obscuration and approximate reflection loss as estimated by spectrophotometry presented herein and in prior works. ${ }^{1,19}$

Figure 1(a) shows the RHEED pattern of the $\mathrm{Ni}_{0.54} \mathrm{Mg}_{0.46} \mathrm{O}$ film immediately after growth ([110] azimuth). Streakiness and relative brightness of the pattern implies good long range lateral surface order of the film. An RBS spectrum of the film is shown in Fig. 1(b) with the experimental data (symbols) overlaid by the modeled backscattered spectrum (solid). The Ni concentration was determined to be $54 \%(x=0.54)$ and the RBS spectrum indicates that the film is approximately $175 \mathrm{~nm}$ thick, as was confirmed by profilometry. In Fig. 1(c), the XRD spectrum illustrates the highly oriented nature of the $\mathrm{Ni}_{\mathrm{x}} \mathrm{Mg}_{1-\mathrm{x}} \mathrm{O}$ film as well as its cubic phase and (001) orientation. A standard $\theta-2 \theta$ scan was executed over the range $10^{\circ} \leq 2 \theta \leq 90^{\circ}$. The only peaks observed for the film are attributed to the (001) and (002) lattice planes, of which the (002) was stronger by more than two orders of magnitude. The full-width half-maximum of the (002) peak was fitted to be $0.19^{\circ}$. The (111) diffraction peak would appear as the second most intense peak for randomly oriented polycrystalline $\mathrm{NiO}$ and would be located at $2 \theta=36.939^{\circ}$ for this stoichiometry. This peak's absence in

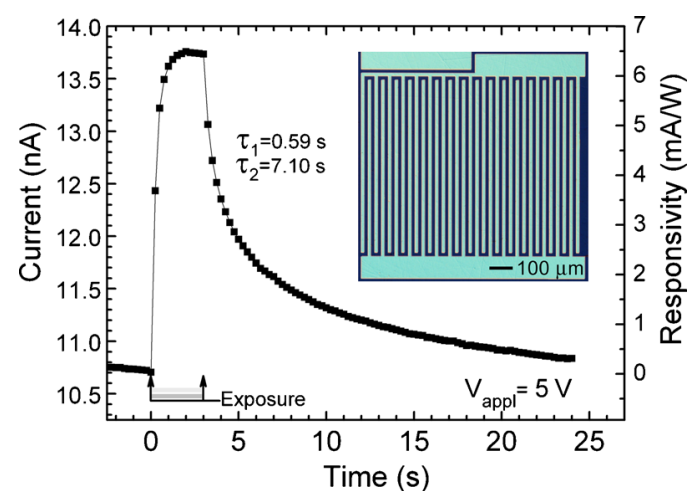

FIG. 2. (Color online) Photocurrent generated through the device (and corresponding responsivity) by $250 \mathrm{~nm}$ light. Inset shows the standard contact device geometry used.

the spectrum further demonstrates the oriented character of the film. Figure 1(d) shows the transmission of the film illustrating the abrupt DUV material band-edge absorption. A simple linear extension of the film's transmission edge to the $\lambda$-axis indicates a transmission cutoff wavelength of approximately $283 \mathrm{~nm}$.

The $\mathrm{Ni}_{0.54} \mathrm{Mg}_{0.46} \mathrm{O}$ devices were found to exhibit a persistent photoconductivity commensurate with that often observed in photoconductive devices. ${ }^{20-22}$ Persistent photoconductivity was observed in these films by the authors previously and is found to be reduced with proper growth conditions (in general, higher substrates temperatures and reduced growth rates) and postgrowth treatment not discussed here. Figure 2 exemplifies this photocurrent persistence when a device (contact separation of $5 \mu \mathrm{m}, \mathrm{V}_{\text {applied }}=5 \mathrm{~V}$ ) is illuminated by DUV light $\left(\lambda=250 \mathrm{~nm}, \mathrm{P}_{\text {incident }} \approx 400 \mathrm{nW}\right)$ for $3 \mathrm{~s}$. The induced photocurrent response saturates in fewer than $2 \mathrm{~s}$ of exposure. Upon ceasing illumination, measureable photocurrent persists for more than $20 \mathrm{~s}$. The response decay is best fit by a two-term exponential form $[\mathrm{R}(\mathrm{t})=\mathrm{A}$ $\left.+\mathrm{B} e^{-\mathrm{t} / \tau 1}+\mathrm{C} e^{-\mathrm{t} / \tau 2}\right]$. The faster of the two decay constants is likely associated with capacitive effects of the large-area devices, while the slower constant is attributed to presently unidentified deep-level defects shown to be associated with persistent photoconductivity. For the device shown the time constants are fitted to be $\tau_{1}=0.59 \mathrm{~s}$ and $\tau_{2}=7.10 \mathrm{~s}$.

Device responsivities and dark currents were measured over the range of voltages which were found to promote stable, consistent device behavior. Maximum voltages were $10 \mathrm{~V}, 75 \mathrm{~V}$, and $100 \mathrm{~V}$ for $5 \mu \mathrm{m}, 10 \mu \mathrm{m}$, and $15 \mu \mathrm{m}$ detector contact separations, respectively. Device peak responsivities as a function of applied voltage are plotted in Fig. 3(a). All devices were found to have approximately the same peak-response wavelength of $250 \mathrm{~nm}$ (the spectral resolution limits of measurement were $\Delta \lambda=5 \mathrm{~nm}$ ). The differential device responsivities (change in responsivity with respect to voltage) were found to be approximately $1.19 \mathrm{~mA} \mathrm{~W}^{-1} \mathrm{~V}^{-1}$, $0.18 \mathrm{~mA} \mathrm{~W}^{-1} \mathrm{~V}^{-1}$, and $0.016 \mathrm{~mA} \mathrm{~W}^{-1} \mathrm{~V}^{-1}$ for $5 \mu \mathrm{m}$, $10 \mu \mathrm{m}$, and $15 \mu \mathrm{m}$ separations, respectively. The maximum observed responsivity was $12 \mathrm{~mA} / \mathrm{W}$ measured in the 5 - $\mu \mathrm{m}$-separation device at an applied voltage of $10 \mathrm{~V}(\lambda$ $=250 \mathrm{~nm})$. Devices also exhibited linear I-V characteristics with low dark current, as illustrated in Fig. 3(b), with all measured dark currents less than approximately $25 \mathrm{nA}$. Device resistances were $0.45,2.7$, and $31 \mathrm{G} \Omega$ in order of increasing contact separation. Both responsivity and resistance 


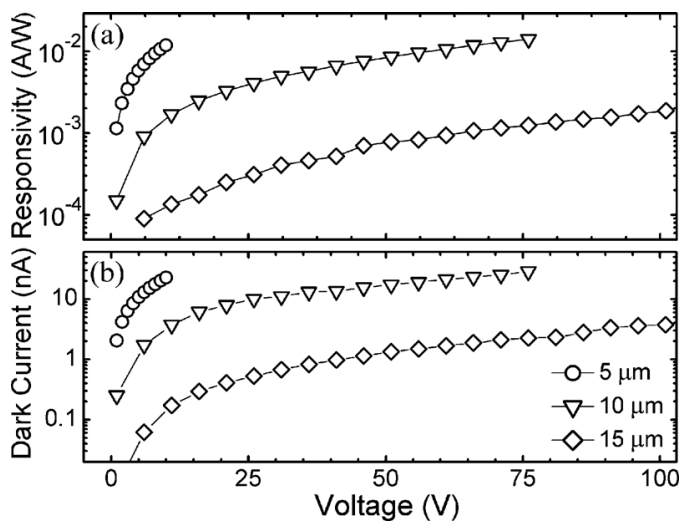

FIG. 3. (a) The voltage-dependent photoconductor responsivity at peakresponse wavelength and (b) the corresponding device dark current.

values scaled approximately as expected by accounting for changes in contact separation and effective conduction channel length. ${ }^{23}$ It should be noted that long carrier lifetimes are often associated with high device gain, sometimes leading to responsivities greater than unity quantum efficiency. However, the high resistance of these films-likely due to low carrier mobility observed in such ionic compounds-limits the gain of these devices. Interrogation of these compounds by Hall measurement is therefore an important continuation of this study.

Finally, the spectral response of the photoconductors is exemplified in Fig. 4. The device response spectrum (5 $\mu \mathrm{m}$ contact separation, $\mathrm{V}_{\text {applied }}=10 \mathrm{~V}$ ) exhibits a clear response edge around $300 \mathrm{~nm}$. As stated, the maximum responsivity is measured at $\lambda=250 \mathrm{~nm}$ and is approximately $12 \mathrm{~mA} / \mathrm{W}$. The DUV:visible (DUV:VIS) rejection ratio $\left(\mathrm{R}_{250 \mathrm{~nm}} / \mathrm{R}_{400 \mathrm{~nm}}\right)$ is found to be approximately 800:1.

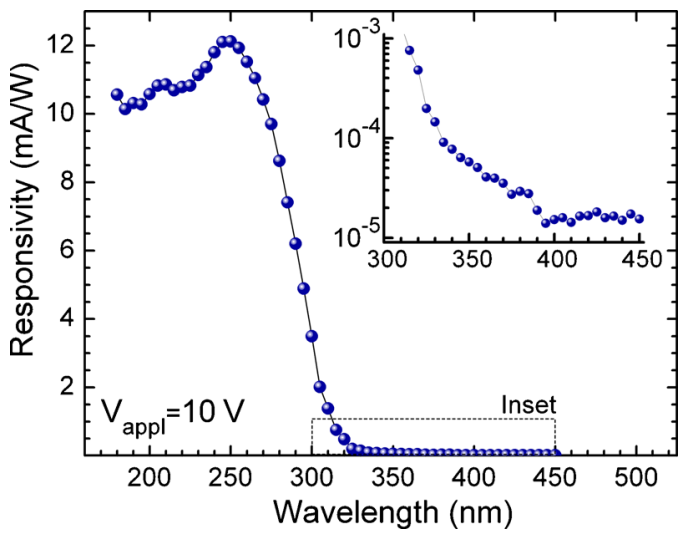

FIG. 4. (Color online) $\mathrm{Ni}_{\mathrm{x}} \mathrm{Mg}_{1-\mathrm{x}} \mathrm{O}$ photoconductor spectral responsivity. The devices exhibit abrupt UVC response-cutoff and a DUV:VIS rejection ratio of 800:1.
In summary, this work describes the growth and characterization of an epitaxial $\mathrm{Ni}_{0.54} \mathrm{Mg}_{0.46} \mathrm{O}$ thin film on approximately lattice-matched $\mathrm{MgO}(100)$ and its subsequent application in photoconductive DUV detectors. Photoconductors with various contact separations $(5,10$, and $15 \mu \mathrm{m})$ were fabricated by deposition of interdigitated $\mathrm{Pt} / \mathrm{Au}$ contacts and characterized in terms of temporal response, spectral response, and voltage-dependence of responsivity and dark current. Distinct DUV responsivity $\left(\lambda_{\text {peak }}=250 \mathrm{~nm}\right)$ with good visible rejection (800:1 selectivity) and high peak responsivity $\left(\mathrm{R}_{\max }=12 \mathrm{~mA} / \mathrm{W}\right)$ demonstrate the applicability of this ternary compound to DUV optoelectronic applications.

${ }^{1}$ J. W. Mares, R. C. Boutwell, M. T. Falanga, A. Scheurer, and W. V. Schoenfeld, Proceedings of MRS 2009 Fall Meeting (Mater. Res. Soc. Symp. Proc., Warrendale, 2009), Vol. 1201.

${ }^{2}$ H. F. Wong, K. H. Wong, and C. H. Lau, Phys. Status Solidi A 206, 2202 (2009)

${ }^{3}$ Z. G. Ji, Z. P. He, K. Liu, S. C. Zhao, and Z. J. He, J. Cryst. Growth 273, 446 (2005).

${ }^{4}$ Y. Zhao, J. Zhang, D. Jiang, C. Shan, Z. Zhang, B. Yao, D. Zhao, and D. Shen, J. Phys. D: Appl. Phys. 42, 092007 (2009).

${ }^{5}$ N. B. Chen and C. H. Sui, Mater. Sci. Eng., B 126, 16 (2006).

${ }^{6}$ S. Choopun, R. D. Vispute, W. Yang, R. P. Sharma, T. Venkatesan, and H. Shen, Appl. Phys. Lett. 80, 1529 (2002).

${ }^{7}$ A. Ohtomo, M. Kawasaki, T. Koida, K. Masubuchi, H. Koinuma, Y. Sakurai, Y. Yoshida, T. Yasuda, and Y. Segawa, Appl. Phys. Lett. 72, 2466 (1998).

${ }^{8}$ Z. G. Ju, C. X. Shan, D. Y. Jiang, J. Y. Zhang, B. Yao, D. X. Zhao, D. Z. Shen, and X. W. Fan, Appl. Phys. Lett. 93, 173505 (2008).

${ }^{9}$ S. Lany, J. Osorio-Guillen, and A. Zunger, Phys. Rev. B 75, 241203 (2007)

${ }^{10}$ U. S. Joshi, Y. Matsumoto, K. Itaka, M. Sumiya, and H. Koinuma, Appl. Surf. Sci. 252, 2524 (2006).

${ }^{11}$ L. Ai, G. Fang, L. Yuan, N. Liu, M. Wang, C. Li, Q. Zhang, J. Li, and X. Zhao, Appl. Surf. Sci. 254, 2401 (2008).

${ }^{12}$ Y. M. Lu, W. S. Hwang, J. S. Yang, and H. C. Chuang, Thin Solid Films 420-421, 54 (2002).

${ }^{13}$ M. Eleruja, G. Egharevba, O. Abulude, O. Akinwunmi, C. Jeynes, and E. Ajayi, J. Mater. Sci. 42, 2758 (2007).

${ }^{14}$ H. Ohta, M. Hirano, K. Nakahara, H. Maruta, T. Tanabe, M. Kamiya, T. Kamiya, and H. Hosono, Appl. Phys. Lett. 83, 1029 (2003).

${ }^{15}$ A. M. Salem, M. Mokhtar, and G. A. El-Shobaky, Solid State Ionics 170, 33 (2004).

${ }^{16}$ J. S. Choi, H. Y. Lee, and K. H. Kim, J. Phys. Chem. 77, 2430 (1973).

${ }^{17}$ A. Kuzmin and N. Mironova, J. Phys.: Condens. Matter 10, 7937 (1998).

${ }^{18}$ A. Kuzmin, N. Mironova, J. Purans, and A. Rodionov, J. Phys.: Condens. Matter 7, 9357 (1995).

${ }^{19}$ J. W. Mares, R. C. Boutwell, A. Scheurer, M. Falanga, and W. V. Schoenfeld, Proc. SPIE 7603, 76031B (2010).

${ }^{20}$ S. J. Chung, M. S. Jeong, O. H. Cha, C.-H. Hong, E. K. Suh, H. J. Lee, Y. S. Kim, and B. H. Kim, Appl. Phys. Lett. 76, 1021 (2000).

${ }^{21}$ C. V. Reddy, K. Balakrishnan, H. Okumura, and S. Yoshida, Appl. Phys. Lett. 73, 244 (1998).

${ }^{22}$ V. S. Vavilov, P. C. Euthymiou, and G. E. Zardas, Phys. Usp. 42, 199 (1999).

${ }^{23}$ E. Rosencher and B. Vinter, Optoelectronics (Cambridge University Press, Cambridge, 2002). 